\title{
IMPACT OF DG ON POWER SYSTEM FAULTS IN RADIAL DISTRIBUTION SYSTEM
}

\author{
T.Murali Mohan \\ Department of EEE \\ UCEK, JNTUK A.P, INDIA
}

\begin{abstract}
The Purpose of protection equipment in the power system is to disconnect the faulty part and minimizing the damage caused by the faults. Pickup value of fault current plays a major role for the operation of protection equipment. Therefore, before connecting protection equipment to the network fault analysis is done for setting the pickup value of fault current. But with the insertion of DG to the network the magnitude of fault current is increased. Due to this increased fault current relays mall operate operation of the protection equipment disturbed. So that fault current calculations are needed before inserting DG to the network. In this work mainly focused on balanced three phase radial distribution network. MATLAB software is used for modeling the network and simulation of results under different fault conditions. Fault currents are found out under different fault conditions like LG, LL, LLG and LLLG without any insertion of DG to the network. Fault currents are found out to the same network with the insertion of DG for the above fault conditions and compare the results with DG and without DG.
\end{abstract}

Keywords - Distributed generation(DG), Line to ground fault (LG), Line to line fault (LL), Double line to ground fault(LLG), Three phase to ground fault (LLLG)

\section{INTRODUCTION}

In radial distribution system power flow is unidirectional that means power is flow from grid to the load. The protection equipment used in the radial distribution system designed to operate in unidirectional power flow. The fault current flows in radial distribution is flows from grid to load, and they will not be designed operate in bidirectional power flow. The pickup values of protection equipment are fixed at designed stage. IEEE publisher (2007) and Youngwook Kim et al.(2016) addressed the relays operation and superconducting fault current operation in the distribution system [1-2].

But in the present smart grid distributed generation plays a major role due to automation of every system in the world leads to increasing demand for the electricity. With the increasing demand increasing of power generation is not recommended, by the consideration of transmission and distribution lines cost point of view. Hence DG in distribution network is the best alternative solution to meet the increased load demand. Thong Vu van et al. (2005) and Metra K (2015)

\author{
G.Anjali Devi \\ Department of EEE \\ UCEK, JNTUK, A.P, INDIA
}

addressed the DG integration and its impact on distribution system [3-4].

But with the insertion of DG into the network causes the increase in fault current magnitude and direction power flow is bidirectional. With the increased fault current the existing protection equipment may mall operate and coordination of protection system disturbed. Operation of power system will be damaged. Hence before inserting DG into the network fault analysis was done. Muhammad Aslam Usailin et al. (2014) and Dulan Lucian Ioan (2014) addressed the impact of DG on the fault current in distribution system [5-6].

\section{FAULTS IN POWER SYSTEM}

Power system operate at different voltage and current levels so it is necessary to covert the all the ratings into a common value called per unit quantities with the common base value. Reactance diagram is used for unsymmetrical fault analysis. Symmetrical faults are analyzed using bus impedance matrix and by using the venin's theorem. Faults in power system can be classified into two types and they are 1.Symmetrical faults 2.Unsymmetrical faults .William patrick Davis (2012) addressed the faults in transmission line [7].In the symmetrical faults the fault current flowing in the three phases are equal in magnitude, it is also called as balanced fault three phase fault is an symmetrical fault. In the unsymmetrical faults the fault current flowing in the each phase is different in magnitude. Symmetrical components are used for the unsymmetrical fault analysis. LG, LL and LLG faults are the examples of the unsymmetrical faults.

\section{A.Line to ground fault-}

Figure 1 shows the line to ground fault occurred at point $\mathrm{k}$ in phase a through fault impedance.

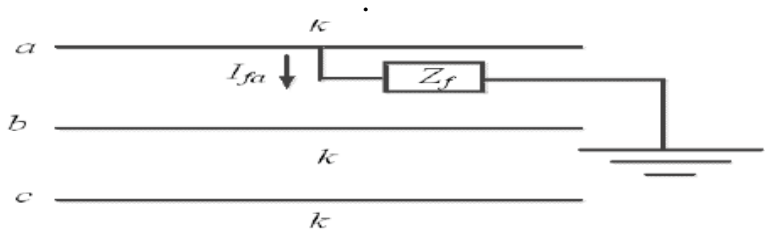

Fig.1. Line to ground fault in phase a

$\mathrm{Ia} 1=(\mathrm{Vpf}) /((\mathrm{Z} 1+\mathrm{Z} 2+\mathrm{Z} 0)+3 \mathrm{Zf})$

$\mathrm{Ia} 1=\mathrm{Ia} 2=\mathrm{Ia} 0$ 


\section{International Journal of Engineering Applied Sciences and Technology, 2019 \\ Vol. 4, Issue 6, ISSN No. 2455-2143, Pages 278-282 \\ Published Online October 2019 in IJEAST (http://www.ijeast.com)}

$$
\begin{gathered}
\text { Ifa }=3 \text { Ia } 1 \\
I_{b}=0, I_{c}=0
\end{gathered}
$$

Where $I_{a 0}, I_{a 1}, I_{a 2}$ are the zero, positive and negative sequence componenets of current.

Where $\mathrm{I}_{\mathrm{b}}$ and $\mathrm{I}_{\mathrm{c}}$ are the current flowing in the phases $\mathrm{b}$ and $\mathrm{c}$

$\mathrm{V}_{\mathrm{pf}}=$ Prefault voltage

$\mathrm{I}_{\mathrm{fa}}=$ Fault current in phase a

$\mathrm{Z}_{0}, \mathrm{Z}_{1}$ and $\mathrm{Z}_{2}$ are the zero, positive and negative sequence componenets of impedance.

\section{$\mathrm{Z}_{\mathrm{f}}=$ Fault impedance}

The magnitude of fault current value depends on the impedance value. Single line to ground fault is the most common type of faults occurring in the distribution systems.

\section{B. Line to Line fault -}

Figure 2 shows the line to line fault occurred at point $\mathrm{k}$ in phase $b$ and $c$ phases through fault impedance. The magnitude of fault current value is depends on the impedance value. The fault current is flowing in the $\mathrm{b}$ and $\mathrm{c}$ phases.

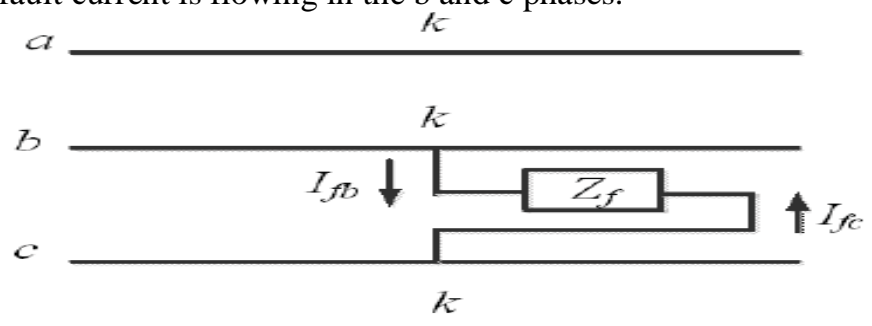

Fig.2. Line to Line fault in phase's b and c

$\mathrm{I}_{\mathrm{fb}}=-\mathrm{I}_{\mathrm{fc}}$

$\mathrm{I}_{\mathrm{a} 1}=\left(\mathrm{V}_{\mathrm{pf}}\right) /\left(\mathrm{Z}_{1}+\mathrm{Z}_{2}+\mathrm{Z}_{\mathrm{f}}\right)$

$\mathrm{I}_{\mathrm{a} 2}=-\mathrm{I}_{\mathrm{a} 1}$

$\mathrm{I}_{\mathrm{a} 0}=0, \mathrm{I}_{\mathrm{a}}=0$

The fault current is calculated from the symmetrical components.

\section{Double Line to ground fault-}

Figure 3 shows the double line to fault occurred at point $k$ in phases $b$ and $c$ through fault impedance.

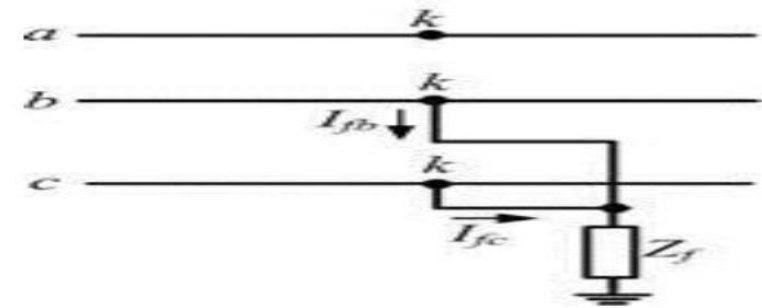

Fig.3. Double line to ground fault occurred in phase's band c

$$
\begin{aligned}
& \mathrm{I}_{\mathrm{a}}=0 \\
& \mathrm{I}_{\mathrm{a} 0}=-\left(\mathrm{I}_{\mathrm{a} 1}+\mathrm{I}_{\mathrm{a} 2}\right) \\
& \mathrm{I}_{\mathrm{a} 2}=\mathrm{V}_{\mathrm{a} 2} / \mathrm{Z}_{2} \\
& \mathrm{~V}_{\mathrm{a} 2}=\mathrm{V}_{\mathrm{a} 1} \\
& \mathrm{~V}_{\mathrm{a} 1}=\mathrm{V}_{\mathrm{pf}}-\mathrm{Z}_{1} \mathrm{I}_{\mathrm{a} 1} \\
& \mathrm{I}_{\mathrm{a} 1}=\frac{V_{p f}}{z_{1}+\frac{\mathrm{I}_{2}\left[z_{0}+3 z_{f}\right)}{z_{2}+z_{0}+3 x_{f}}} \\
& \mathrm{I}_{\mathrm{f} \mathrm{b}}=\mathrm{I}_{\mathrm{fc}}=3 \mathrm{I}_{\mathrm{a} 0} \\
& \mathrm{I}_{\mathrm{a} 0}=-\left(\mathrm{I}_{\mathrm{a} 1}+\mathrm{I}_{\mathrm{a} 2}\right)
\end{aligned}
$$

\section{Three phase to ground fault-}

Figure 4 shows the three phase to ground fault occurred at point $\mathrm{k}$. The fault current flowing in the three phases are equal. And the value of fault current magnitude depends on the fault impedance.

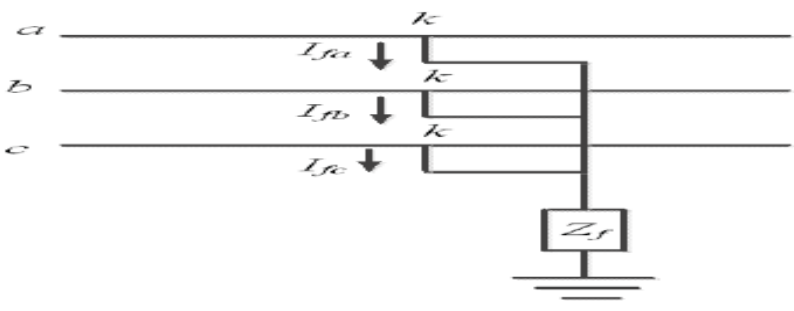

Fig.4. Three phase to ground fault through fault impedance

The order of severity of faults in the power system are LLLG, LLG, LL and LG. Probability of occurrence of faults in power system are LG(70\%), LL(15\%), LLG(10\%), LLLG(5\%).

\section{DISTRIBUTED GENERATION IN POWER SYSTEM}

DGs are small scale generating units up to the rating of 10MW.And they are connected to the placed at near to load centers. As the fast growing technology of power system distributed generation plays a vital role. DGs are made with renewable energy sources in order to decrease the environmental pollution compared to the traditional grids uses fuel as coal and oil. DGs are renewable energy sources like solar, wind, biomass and hydro power generation. DG to the system increases the advantages like improved voltage profile, transmission and distribution line losses reduced, transmission and distribution lines cost can be reduced, satisfying of the load during the peak hours. Insertion of DG to the network also causes the disadvantages like power flow direction is reversed, increased in the fault current magnitude, false tripping of healthy feeders and voltage fluctuation. Ekuel A.O et al. (2015) and Pepermanns G et al. (2005) addressed the DG in distribution system [8-9]. There are many negative impacts occur in the system due insertion of DG into the network. Kauhaniemi K et al.(2004) and Barker P et al.(2000) addressed the impact of DG in power system protection [10- 


\section{International Journal of Engineering Applied Sciences and Technology, 2019 \\ Vol. 4, Issue 6, ISSN No. 2455-2143, Pages 278-282 \\ Published Online October 2019 in IJEAST (http://www.ijeast.com)}

11]. In the traditional radial distribution system power flow is unidirectional but with the insertion of DG causes the power flow is bidirectional, with the bidirectional power flow existing protection equipment mall operate. Without integration of DG into the network the fault current supplied by the source only. But with the integration of DG into the network causes the increase in fault current magnitude. The fault current supplied by the both source and DG hence the level of fault current can be increased Digambar $\mathrm{R}$ et al.(2017)addressed the impact of DG in the fault current and fault current limiter in distribution system [12]. Suppose two feeders are from a sub station and DG is connected to the one of the feeder. When fault is occur in the next feeder the DG connected healthy feeder feeds fault current through the substation bus bar and healthy feeder relay may mal operate Zayandehroodi Hadi et al. (2011) addressed the impact of DG in protection system [13].

DGs are different types but in this paper renewable energy based hydro power DG is used Akhtar Kalam et al. (2011) addressed the DG operation in smart grid technology [14]. Photo voltaic system:solar energy is primary input fuel for the photo volaic system.Solar energy is freely available in the nature. The fuel cost is zero in the PV system. The output voltage produced from the PV system is DC and it is converted into AC with the help of inverters. Wind power system: The wind power generation depends on speed of the wind. Wind turbine is connected to the shaft of the generator to produce power. Hydropower generation:Water at high head used for the hydro power generation.Hydro power generation is the renewable energy power generation and environmental pollution free generation.

\section{RADIAL DISTRIBUTION SYSTEM WITHOUT DG}

Figure 5 is single line diagram of radial distribution network without any connecting DG to the network.

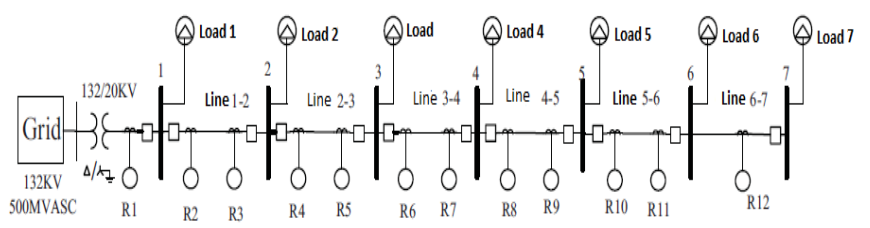

Fig.5. single line diagram of radial distribution network

The lines and load data is given in the appendix. It consists of 7 bus radial balanced three phase three wire distribution network. Grid is an synchronous machine type and it is connected to the network through $132 / 20 \mathrm{KV}, 30 \mathrm{MVA}$ transformer and it is an delta to star grounded transformer operate at a frequency of 60HZ.Different types of faults like LG, LL, LLG, LLLG applied in line 5-6 Without any connection of DG.

\section{Case 1: LG fault in line 5-6 Without DG-}

Depending on the type of transformer connection the value of fault current varies under LG fault condition. Circuit is running up to $\mathrm{t}=0.6$ seconds, and fault duration time is $\mathrm{t}=0.1$ seconds to 0.4 seconds. Without any protection equipment circuit is simulated under LG fault conditions.

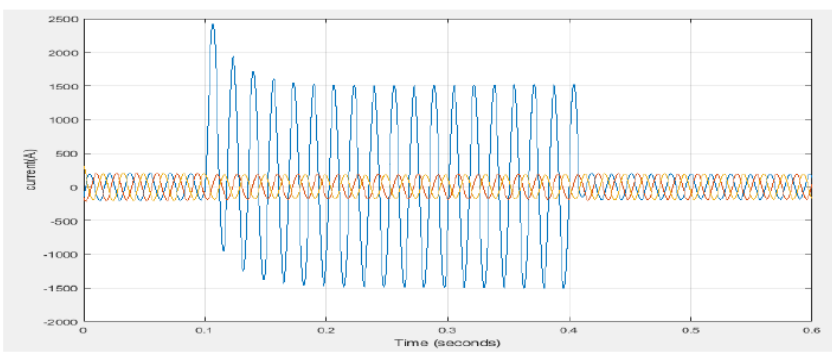

$6(a)$

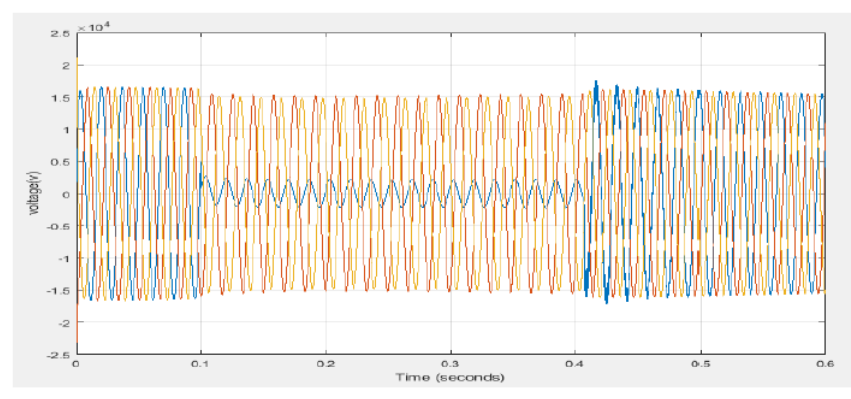

$6(b)$

Fig. 6 ( a) and (b) current and voltage waveforms at bus 5

Before fault the peak value of current in all the three phases is 200A. During fault duration the level of fault current in the phase $\mathrm{A}$ is increased to $1500 \mathrm{~A}$ and the current in the remaing two phases is maintains at 200A. After fault the level of current be maintains at $200 \mathrm{~A}$ in all the three phases.

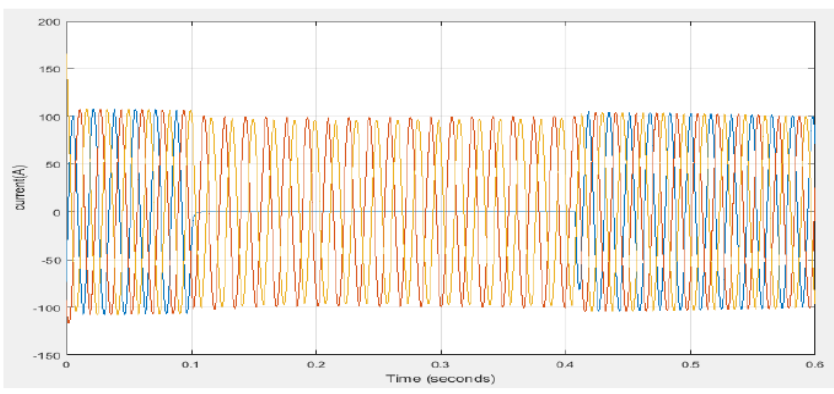

7(a) 


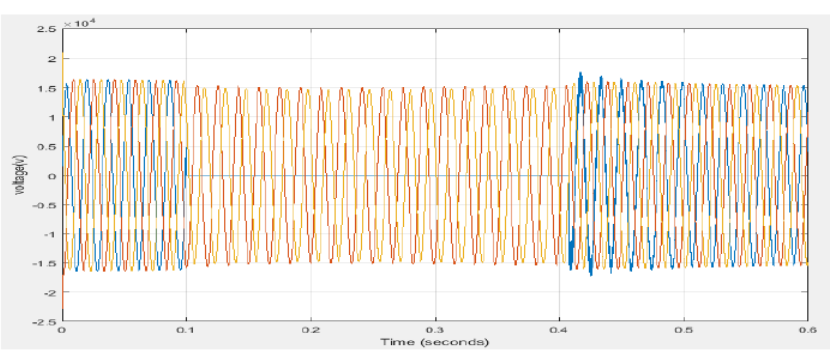

$7(b)$

Fig. 7(a) and 7(b) Current and voltage waveform at bus 6

Before fault at bus 6 the peak value of current in all the three phases is 100A.During fault duration the value of current in the phase $\mathrm{A}$ is zero. The current in the remaing two phases are maintained at the same value. After fault the value of current in the three phases are maintained at 100A.

Case 2: LL fault in line 5-6 Without DG-

Running time of circuit is $\mathrm{t}=0.6$ secondsand fault duration time is $\mathrm{t}=0.1$ seconds to 0.4 seconds. Without any protection equipment circuit is simulated under LL fault conditions.

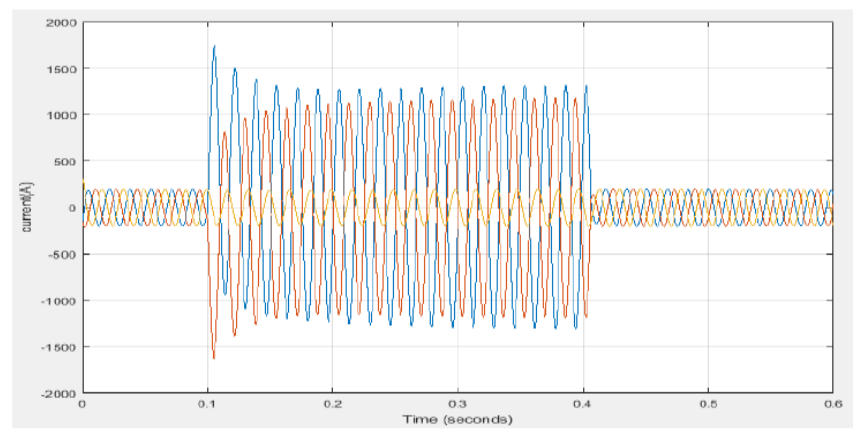

$8(a)$

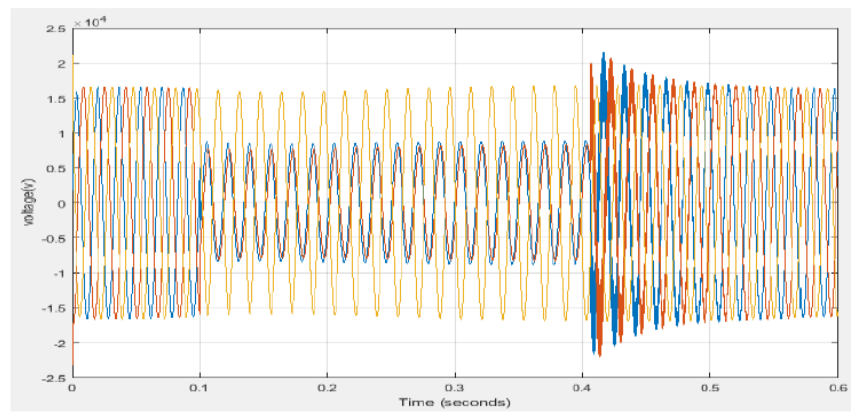

$8(b)$

Fig. 8(a) and 8(b) current and voltage waveform at bus 5

Before fault the peak value of current in all the three phases are 200A.During fault duration the current in faulted phases are A and $\mathrm{B}$ are increased to $1280 \mathrm{~A}$,the remaing phase current is maintained at 200A.After fault duration the level of current in all the three phases are maintains at 200A.

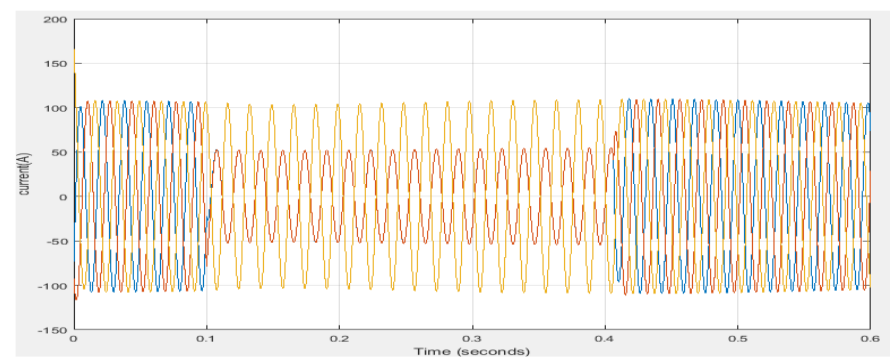

9(a)

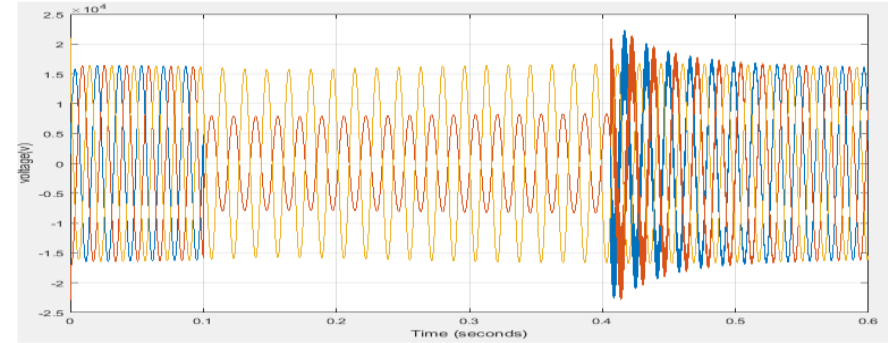

9(b)

Fig. 9(a) and 9(b) Current and voltage waveform at bus 6

Before fault at bus 6 the peak value of current in all the three phases are 100A. During fault duration the value of current in the phase $\mathrm{A}$ is $0 \mathrm{~A}$ and phase $\mathrm{B}$ is 50A.The current in the remaing phase is maintained at the same value 100A. After fault the value of current in the three phases are maintained at 100A.

\section{Case 3: LLG fault in line 5-6: Without DG-}

Running time of circuit is $\mathrm{t}=0.6$ seconds and fault duration time is $\mathrm{t}=0.1$ seconds to 0.4 seconds. Without any protection equipment circuit is simulated under LLG fault condition.
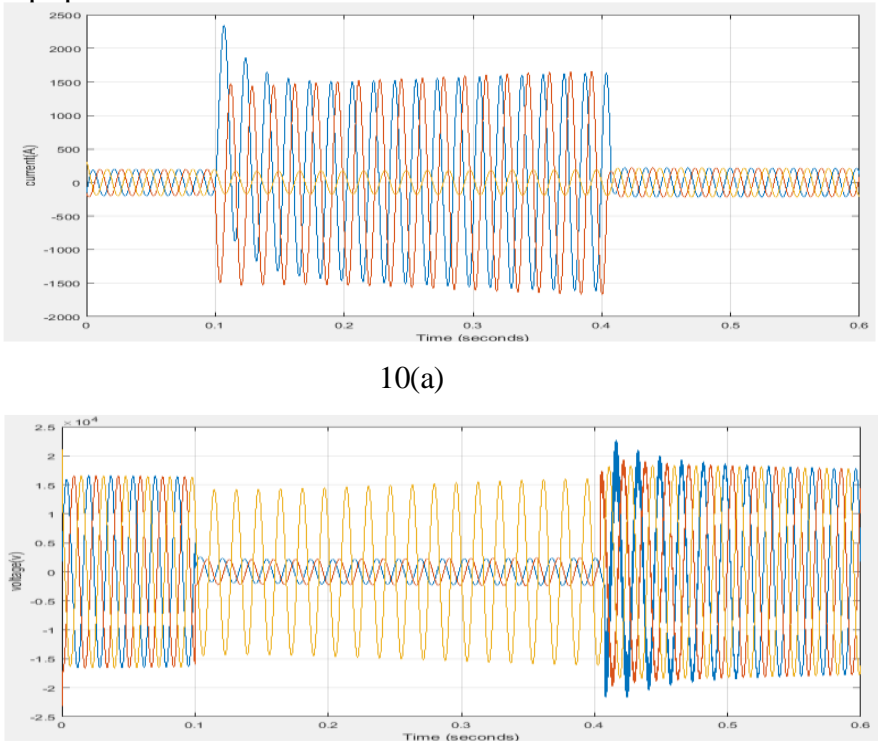

$10(b)$

Fig. 10(a) and 10(b) current and voltage waveforms at bus 5 


\section{International Journal of Engineering Applied Sciences and Technology, 2019 \\ Vol. 4, Issue 6, ISSN No. 2455-2143, Pages 278-282 \\ Published Online October 2019 in IJEAST (http://www.ijeast.com)}

Before fault the peak value of current in all the three phases are 200A.During fault duration the current in faulted phases A and $\mathrm{B}$ are increased to $1500 \mathrm{~A}$, the remaing phase current is maintained at 200A.After fault duration the level of current in all the three phases are maintained at 200A.

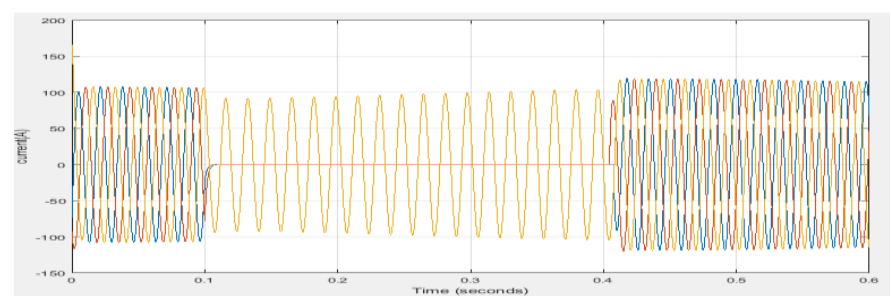

11(a)

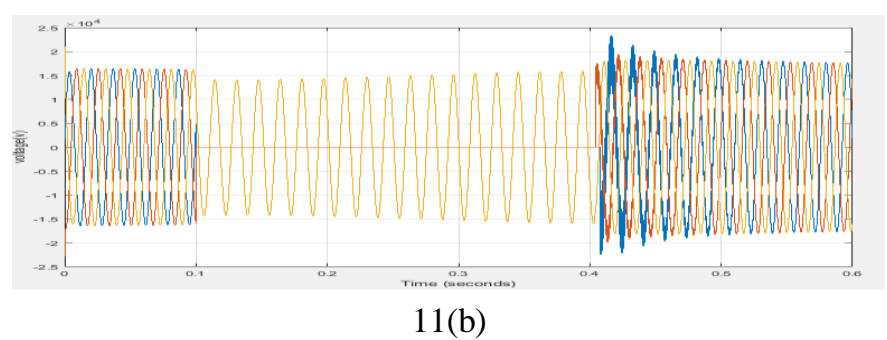

Fig. 11(a) and 11(b) Current and voltage waveform at bus 6

Before fault at bus 6 the peak value of current in all the three phases are 100A.During fault duration the value of current in the phase $\mathrm{A}$ is $0 \mathrm{~A}$ and phase $\mathrm{B}$ is $0 \mathrm{~A}$. The current in the remaing phase is maintained at the same value of $100 \mathrm{~A}$. After fault the value of current in all the three phases are maintained at $100 \mathrm{~A}$.

\section{Case 4: LLLG fault in line 5- 6: Without DG-}

Running time of circuit is $\mathrm{t}=0.6$ seconds, and fault duration time is $\mathrm{t}=0.1$ seconds to 0.4 seconds. Without any protection equipment circuit is simulated under LLLG fault condition.

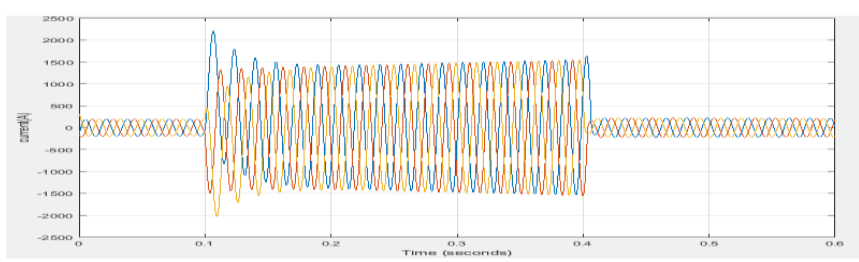

12(a)

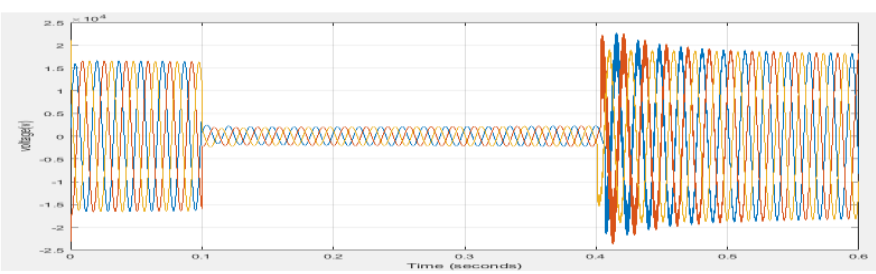

12(b)

Fig. 12(a) and 12(b) current and voltage waveform at bus 5
Before fault the peak value of current in all the three phases are 200A.During fault duration the current in all the three phases are increased to 1500A. After fault duration the level of current in all the three phases are maintained at 200A.

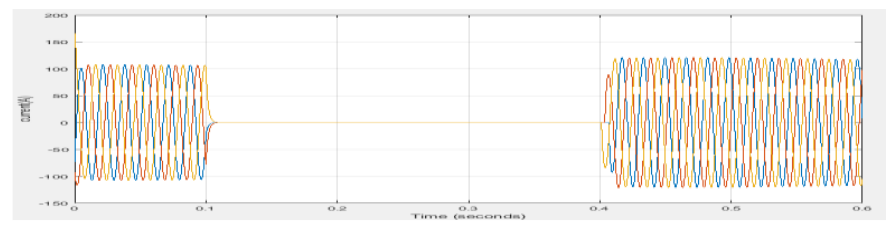

13(a)

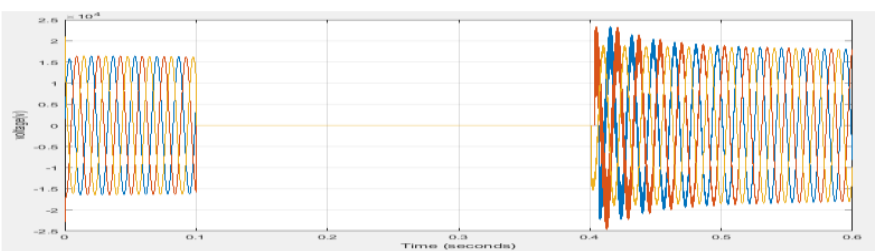

13(b)

Fig. 13(a) and 13(b) current and voltage waveform at bus 6

Before fault at bus 6 the peak value of current in all the three phases are 100A.During fault duration the value of current in the all three phases are 0A.After fault the value of current in all the three phases are maintained at 100A.

\section{RADIAL DISTRIBUTION SYSTEM WITH DG}

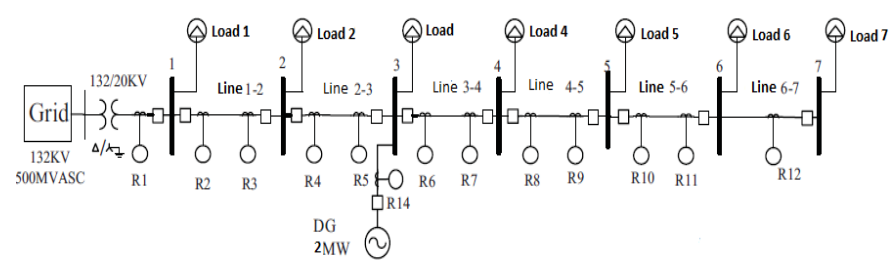

Fig. 14 single line diagram of a network with DG

Hydro power generation is used as a DG in this work. And it is connected at the end of the 2nd bus and starting to the third bus with the $2 \mathrm{MW}$ of power generation. In this work impact of hydro power generation under fault conditions is studied.

\section{Case 1: LG fault in line 5-6 With DG-}

Running time of circuit is $\mathrm{t}=0.6$ seconds and fault duration time is $t=0.1$ to0.4seconds. Without any protection equipment circuit is simulated under LG fault condition.

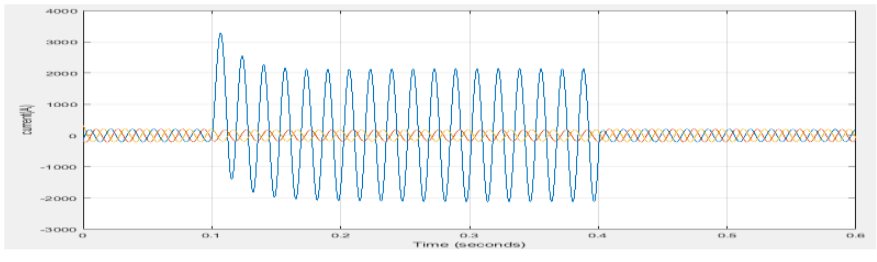

$15(a)$ 


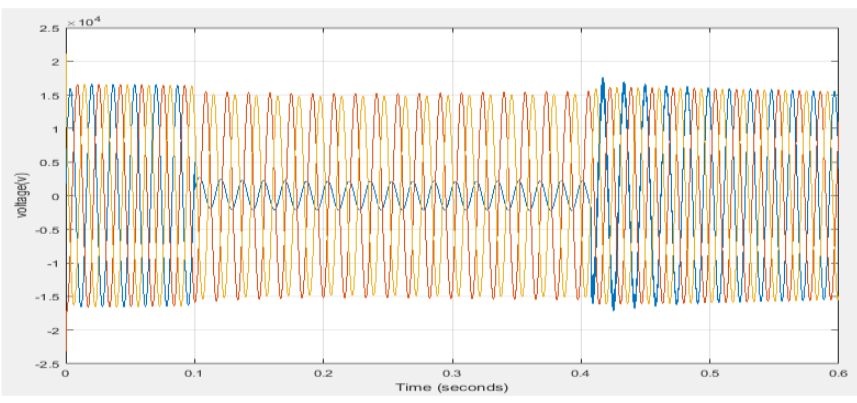

15(b)

Fig. 15(a)and 15(b) current and voltage waveform at bus 5 Before fault the peak value of current in all the three phases are 200A. During fault duration the current in the phase A is increased to $2000 \mathrm{~A}$, the remaing two phases maintained at the same value of 200A. After fault duration the level of current in all the three phases are maintained at 200A.
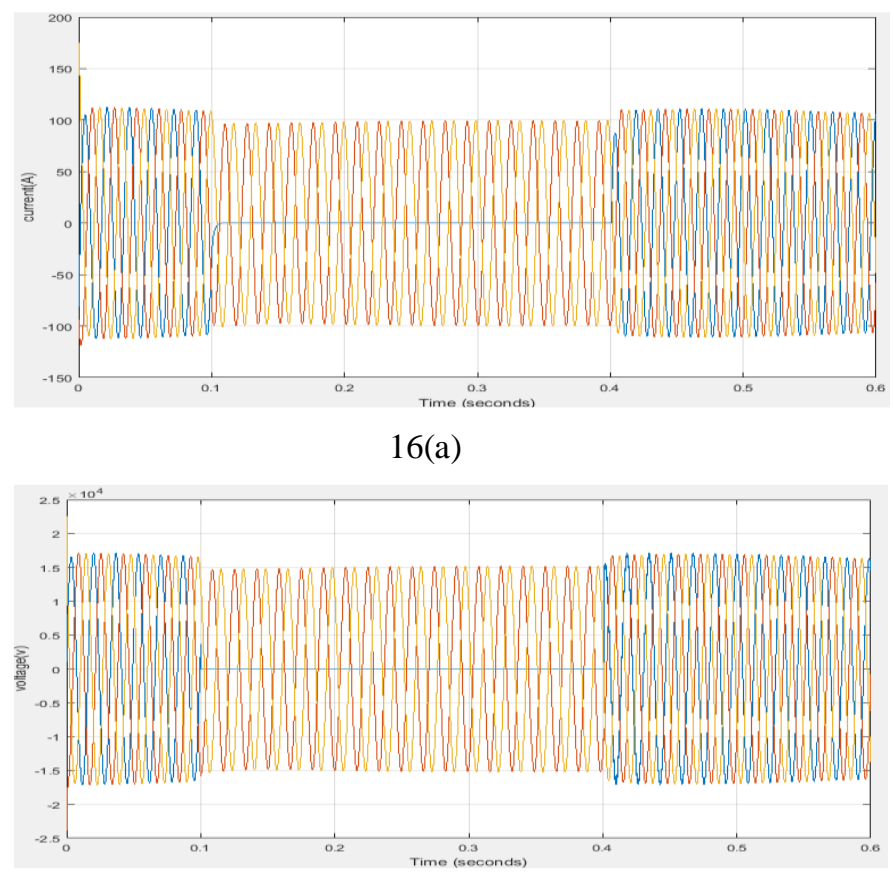

16(b)

Fig.16(a)and 16(b) current and voltage waveform at bus 6

Before fault at bus 6 the current in all the three phases are 100A.During fault duration the value of current in phase $\mathrm{A}$ is $0 A$,the current in the remaing two phases are maintained at same value of 100A.After fault the value of current in all the three phases are maintained at 100A.

\section{Case 2: LL fault in li ne 5-6 With DG-}

Running time of circuit is $\mathrm{t}=0.6$ secondsand fault duration time is $t=0.1$ to 0.4 seconds. Without any protection equipment circuit is simulated under LL fault condition.

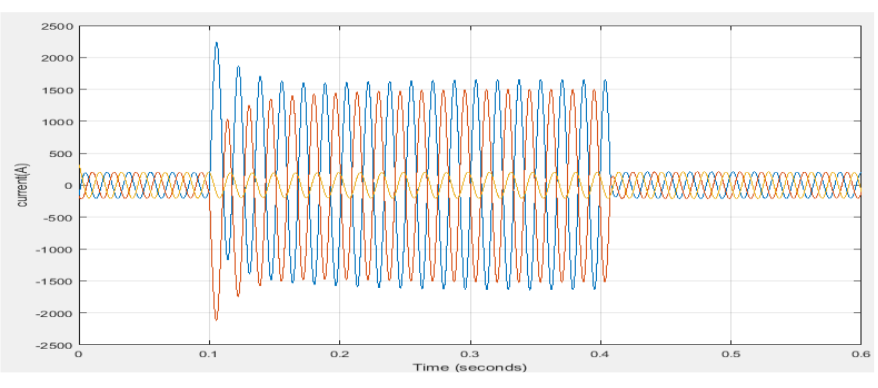

17(a)

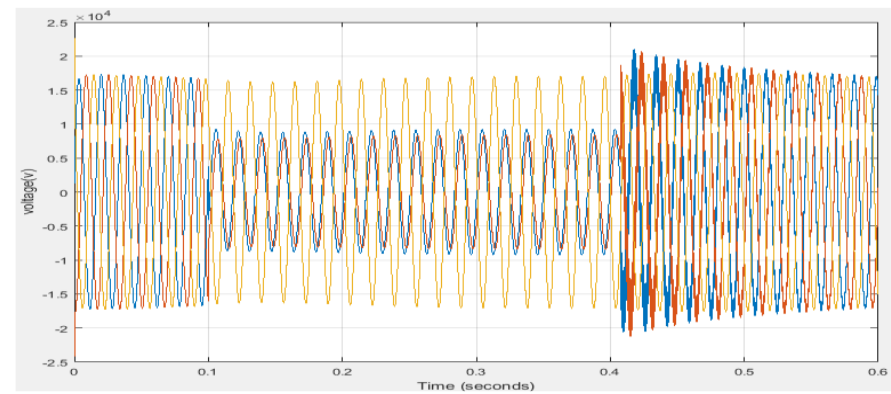

17(b)

Fig. 17(a) and 17(b) current and voltage waveform at bus 5

Before fault the peak value of current in all the three phases are 200A.During fault duration the current in faulted phases are $\mathrm{A}$ and $\mathrm{B}$ are increased to $1500 \mathrm{~A}$, the remaing phase current is maintained at 200A.After fault duration the level of current in all the three phases are maintained at 200A.

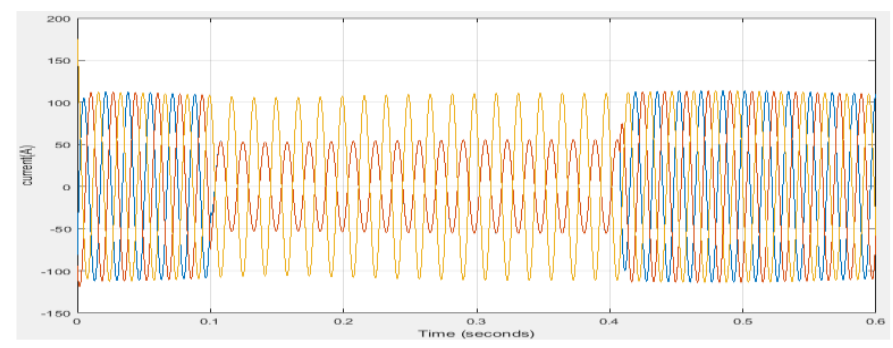

18(a)

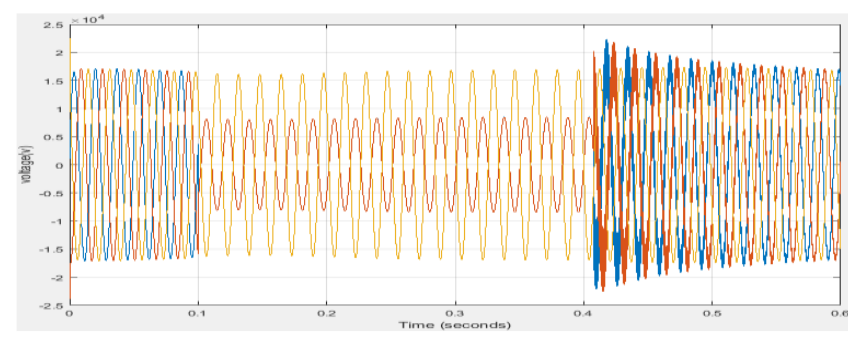

18(b)

Figure 18(a) and 18(b) current and voltage waveform at bus 6 


\section{International Journal of Engineering Applied Sciences and Technology, 2019 \\ Vol. 4, Issue 6, ISSN No. 2455-2143, Pages 278-282 \\ Published Online October 2019 in IJEAST (http://www.ijeast.com)}

Before fault at bus 6 the peak value of current in all the three phases are 100A.During fault duration the value of current in the phase $\mathrm{A}$ is $0 \mathrm{~A}$ phase and $\mathrm{B}$ is $50 \mathrm{~A}$. The current in the remaing phase is maintained at the same value 100A. After fault the value of current in the three phases are maintained at 100A.

\section{Case 3: LLG fault in line 5-6 With DG-}

Running time of circuit is $\mathrm{t}=0.6$ seconds, and fault duration time is $\mathrm{t}=0.1$ to 0.4 seconds. Without any protection equipment circuit is simulated under LLG fault condition.
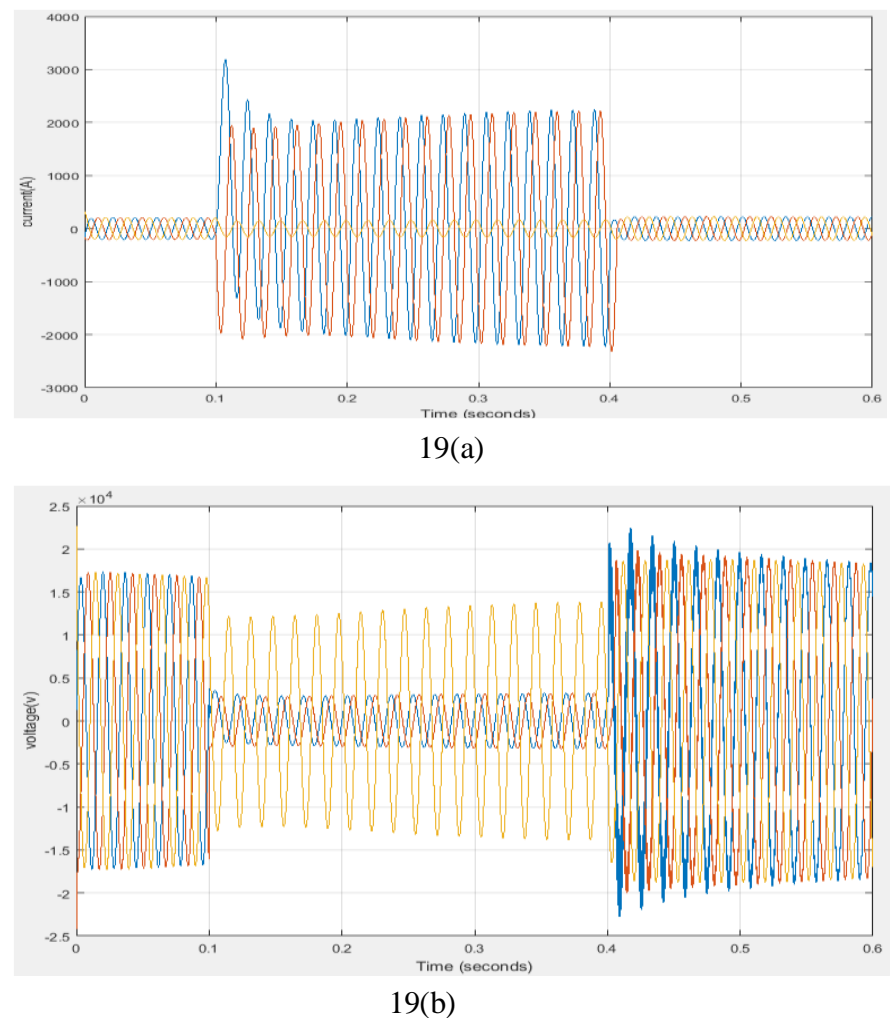

Fig. 19(a) and 19(b) current and voltage waveform at bus 5

Before fault the peak value of current in all the three phases are 200A.During fault duration the current in faulted phases are $\mathrm{A}$ and $\mathrm{B}$ are increased to 2000A,the remaing phase current is maintained at 200A.After fault duration the level of current in all the three phases are maintained at 200A.

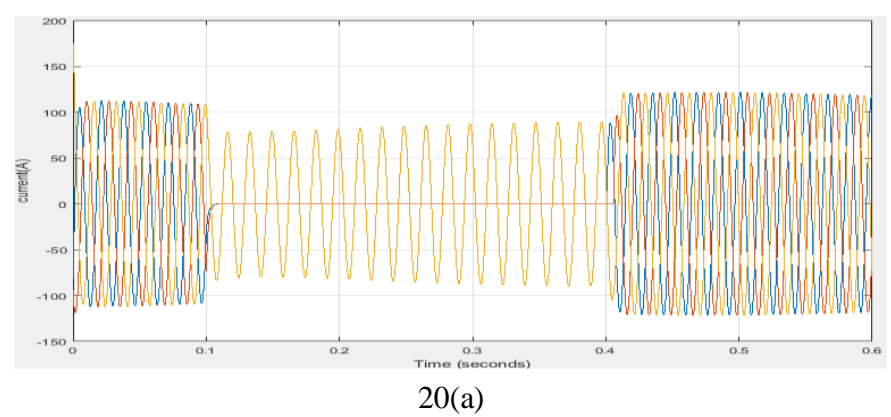

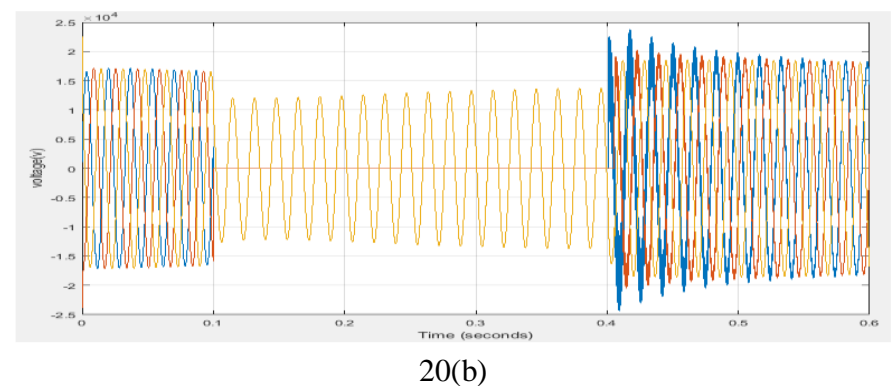

Fig. 20(a) and 20(b) current and voltage waveform at bus 6

Before fault at bus 6 the peak value of current in all the three phases are 100A.During fault duration the value of current in the phase $\mathrm{A}$ is $0 \mathrm{~A}$ and phase $\mathrm{B}$ is $0 \mathrm{~A}$. The current in the remaing phase is maintained at the same value of 100A. After fault the value of current in all the three phases are maintained at $100 \mathrm{~A}$.

\section{Case 4: LLLG fault in line 5-6 With DG-}

Running time of circuit is $t=0.6$ seconds and fault duration time is $\mathrm{t}=0.1$ to 0.4 seconds. Without any protection equipment circuit is simulated under LLLG fault condition.
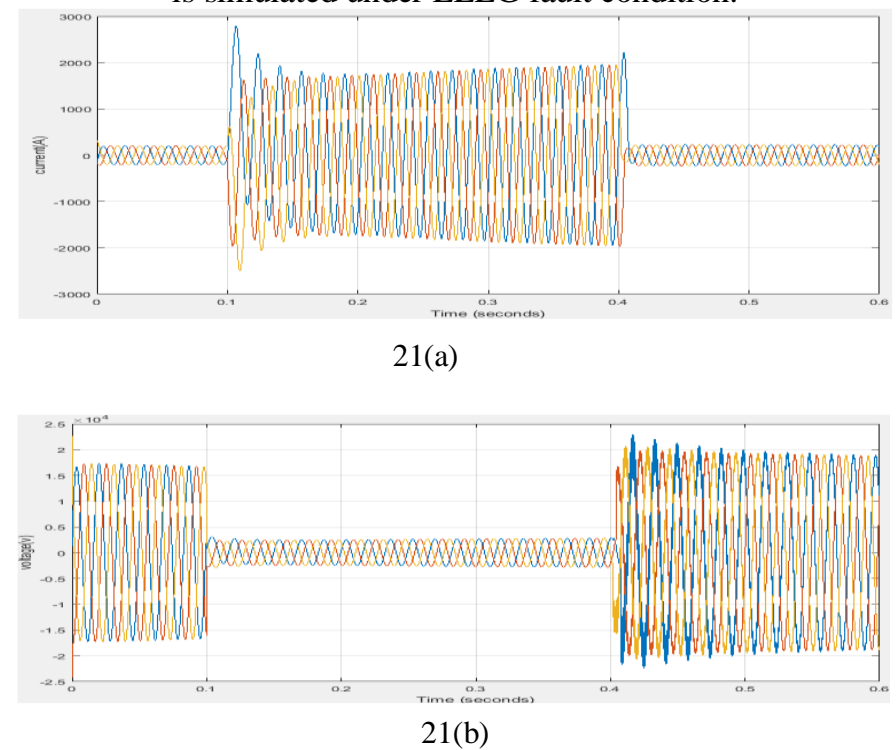

Fig. 21(a) and 21(b) current and voltage waveform at bus 5

Before fault the value of current in all the three phases are 200A.During fault duration the current in all the three phases are increased to $1500 \mathrm{~A}$. After fault duration the level of current in all the three phases are maintained at 200A.

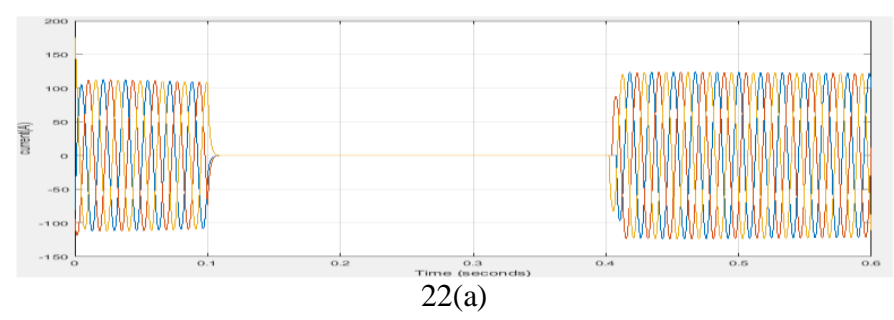




\section{International Journal of Engineering Applied Sciences and Technology, 2019 \\ Vol. 4, Issue 6, ISSN No. 2455-2143, Pages 278-282 \\ Published Online October 2019 in IJEAST (http://www.ijeast.com)}

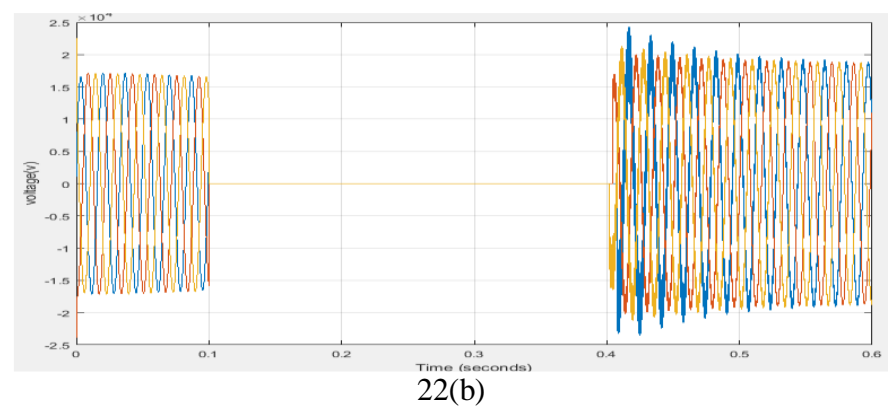

Fig. 22(a) and 22(b) current and voltage waveform at bus 6 Before fault at bus 6 the current in all the three phases are 100A.During fault duration the value of current in the all three phases are 0A.After fault the value of current in all the three phases are maintained at $100 \mathrm{~A}$.

Table -1 Comparision of fault current with DG and without DG

\begin{tabular}{|c|c|c|}
\hline Type of fault & $\begin{array}{c}\text { Without DG } \\
\text { fault current(A) }\end{array}$ & $\begin{array}{c}\text { With DG } \\
\text { fault current(A) }\end{array}$ \\
\hline LG fault & 1500 & 2000 \\
\hline LL fault & 1280 & 1500 \\
\hline LLG fault & 1510 & 2000 \\
\hline LLLG fault & 1500 & 2000 \\
\hline
\end{tabular}

Table 1 shows the comparision fault current with DG and without DG. The level of fault current is increased with insertion of DG to the network.

\section{APPENDIX}

Table -2 Line data

\begin{tabular}{|c|c|c|}
\hline Line id & $\mathbf{R}(\mathbf{o h m s})$ & $\mathbf{L}(\mathbf{H})$ \\
\hline Line 1-2 & 0.0799 & 0.004917 \\
\hline Line 2-3 & 0.1143 & 0.005533 \\
\hline Line 3-4 & 0.196 & 0.0028117 \\
\hline Line 4-5 & 0.342 & 0.00305 \\
\hline Line 5-6 & 0.668 & 0.003395 \\
\hline Line 6-7 & 0.668 & 0.001697 \\
\hline
\end{tabular}

Table-3 load data

\begin{tabular}{|c|c|c|}
\hline Load id & P(MW) & Q(MW) \\
\hline Load 1 & 1.61 & 0.99 \\
\hline Load 2 & $\mathbf{0 . 8 7}$ & $\mathbf{0 . 5 6 2 6}$ \\
\hline Load 3 & $\mathbf{1 . 5 8 6 7}$ & $\mathbf{0 . 9 4 1 4}$ \\
\hline Load 4 & 1.99 & $\mathbf{1 . 3 9 4}$ \\
\hline Load 5 & $\mathbf{1 . 4 2 5 9}$ & $\mathbf{0 . 9 5 8 2}$ \\
\hline Load 6 & $\mathbf{0 . 6 9 3 4 4}$ & $\mathbf{0 . 3 7 4 2}$ \\
\hline Load 7 & $\mathbf{0 . 9 7 9 2}$ & $\mathbf{0 . 6 0 6}$ \\
\hline
\end{tabular}

\section{CONCLUSION}

DG plays a major role in the power system. Hence analysis of the impact of DG on power system is necessary. And in this work impact of DG on radial distribution network is analysed. DG placed mainly at the load side in order to meet the load requirement. Simulations are done for finding the Fault current in radial distribution network, under various fault conditions like LG, LL, LLG and LLLG without any distribution generation to the taken radial distribution network .And observed the fault current values. Simulations are done for the finding fault current in test distribution network, under various fault conditions like LG, LL, LLG, and LLLG with the addition of distribution generation observed the fault current values. Compared the fault current values with DG and without DG and observed the increased fault current value with the addition of distributed generation to the network. By the addition of DG into the network causes the increased in the fault current values.

\section{ACKNOWLEDGEMENT}

I sincerely thank my project supervisor Dr.T.Murali Mohan for his encouragement, and constant technical support extended in carrying out this work. And also thank for his suggestion to write a journal in IJEAST free journal publication. I also thank my parents for their moral support at all the time during my work.

\section{REFERENCE}

[1] IEEE.(2007). Guide for protective relay applications to distribution lines, IEEE std C37.230.

[2] Youngwook Kim,Hyung-chul Jo,Sung Kwan Joo.( June 2016)."Analysis of super conducting fault current limiter Placement on Distributed Generation Expansion “,IEEE Transactions on Applied super conductivity, (Volume:26 ,Issue: 4).

[3] Thong Vu van ,Johan Driesen and Ronnie Belmans .(June 2005)."Interconnection of Distributed Generators and their influences on Power systems",International Energy Journal,(Vol.6,No.1,part 3).

[4] Metra K.(June 2015).”Analysis of Distributed Generation and Impact on Distribution system",International Journal of Advanced Research in Electrical ,Electronics and Instrumentation Engineering (An ISO 3297:2007 Certified Organization),(vol.4,Issue 6).

[5] Muhammad Aslam Usailin Anwar Ali Sahito,Irfan Ahmed Halepoto.(2014).'Impact of Distributed generation on Network Short circuit Level",conference paper.

[6] Dulan Lucian Ioan,Mihali Abrudean and Dorin bica.(2014)."'Effects of Distributed Generation on Electric Power Systems",Procedia Tecnology 12,(pp.681-686).

[7] William patrick Davis.(2012)."Analysis of faults in over head transmission lines".

[8] Ekuel A.O.and Akintunde O.A.(April 2015).’The impact of distributed generation on distribution network", Nigerian journal of technology, (Vol. 34No.2, pp. $325-$ 331). 
[9] Pepermanns G.Driesen J. Haeseldonckx D. Belmans R.and D'haeseleer W.(April 2005)."Distributed generation: definition, benefits and issues",Energy Policy, (vol.33,issue 6, pp.787-798).

[10] Kauhaniemi K. Kumpulainen L.(2004)."Impact of Distributed Generation on the Protection of Distribution Networks", in Proc. IET International Conference on Development in Power System protection.(vol.1, pp.315318).

[11] BarkerP.P.Robert W,Mello De.(July 2000)."Deterrmining the Impact of Distributed Generation on Power Systems: Part 1 - Radial Distribution System". (Vol. 3, 1620,pp.1645-1656).

[12] Digambar R. Bhise Ravishankar, Kankale S. Saurabh Jadhao.(2017)." Impact of Distributed Generation on Protection of Power System ", International Conference on Innovative Mechanisms for Industry Applications ICIMIA,(pp.399-405)

[13] Zayandehroodi Hadi,Mohamed Azaz,Hussain Shareef and Marjan Mohammadjafari.( 18th August 2011)."Impact of distributed generations on power system protection performance",International Journal of the Physical Sciences, (Vol. 6(16),pp. 3999-4007).

[14] AkhtarKalam.HidayatullahN.BlagojceStojecevskiA.(2011 )." Analysis of Distributed Generation Systems ,Smart Grid Technology and Future Motivators Influencing "Change in the Electricity Sector" Smart Grid and Renewable energy, 2(3).(pp.216-229). 